\title{
La música de Julián Bautista durante su exilio en Argentina. Confluencias en la modernidad hispanoamericana
}

\section{The music of Julián Bautista during his exile in Argentina. Confluences in Hispanic American modernity}

\author{
por \\ Julio Ogas \\ Universidad de Oviedo, España \\ jrogas@uniovi.es
}

Julián Bautista (1901-1961) se radica en Argentina luego de que Francisco Franco asumiera el poder en España. Su producción de concierto en esta etapa no es extensa, sin embargo las temáticas que aborda y las características estilísticas de la obras de este período ponen de manifiesto su proceso de adaptación al medio musical que lo acoge. En este trabajo, primero, se realiza un análisis del desarrollo de su estilo compositivo en este período y, posteriormente, se establecen algunas conexiones de este material con el entramado cultural y musical de Buenos Aires.

Palabras clave: Julián Bautista, música argentina, neoclasicismo musical, música española, modernidad hispanoamericana.

Julian Bautista settles in Argentina after Francisco Franco claimed power in Spain. His concert production at this stage is not extensive, however the themes he addresses and the stylistic characteristics of the works of this period show his process of adaptation to the musical environment that welcomes him. In this paper, first, an analysis of the development of his compositional style is made in this period and, later, some connections of this material are established with the cultural and musical framework of Buenos Aires.

Keywords: Julián Bautista, Argentinian music, musical neoclassicism, Spanish music, Hispano-American modernity.

Julián Bautista Cachaza (1901-1961) es uno de los compositores que participa, en la década de 1930, en la conformación del llamado Grupo de los Ocho o Grupo de Madrid ${ }^{1}$. Su carrera se desarrolla en la capital española hasta la llegada del franquismo, momento en el que huye a Francia, luego se traslada a Bélgica y, finalmente, a Buenos Aires, donde va a residir desde 1940 hasta su muerte. Superadas las trabas que el gobierno de la época ponía a los exiliados republicanos, se hace un lugar en la música argentina, con una activa

1 Trabajo realizado en el marco del Proyecto de Investigación I+D+i HAR2015-64285-C2-1-P, Músicas en conflicto en España y Latinoamérica: entre la hegemonía y la transgresión (Siglos XX y XXI). 
participación en la vida musical porteña en tres ámbitos: el de la música para cine, la música de concierto y las clases de composición.

Las obras de concierto que realiza Bautista en Argentina están divididas en dos bloques temporales, las compuestas a mediados de la década de 1940 y las realizadas en la segunda mitad de la década de 1950. Entre las primeras se encuentran: Suite de La dama duende (1944), Fantasía española op. 17 (1945), Catro poemas galegos (1946). Entre las últimas aparecen la cantata Romance del Rey Rodrigo (1956), Sinfonía breve (1956), Segunda sinfonía "Ricordiana" (1957) y el Cuarteto $N^{\circ} 3$ para instrumentos de arco (1958). Además del criterio de separación temporal, las temáticas de estas composiciones también permiten dividirlas en dos grandes grupos: el primero, que iría hasta el Romance y donde la temática española tiene un protagonismo destacado; y el segundo, donde esa temática se retrotrae y adquiere más relevancia la preocupación por los aspectos estructurales y estilísticos ligados a los principios neoclasicistas, pero ahondando en nuevas posibilidades expresivas. El hispanismo, el neoclasicismo y su renovación son aspectos de una modernidad compartida por los músicos de Madrid y Buenos Aires. En este sentido, para los músicos españoles exiliados y para una parte de los músicos argentinos, la temática hispanista tiene un valor ideológico ligado al progresismo y al antifascismo. Por su parte, la renovación del neoclasicismo a partir de incorporar técnicas compositivas provenientes de otras tendencias, unida a la idea de dejar en un plano más subjetivo las alusiones a la música tradicional, constituye, en los años cincuenta, una de las corrientes de modernización que propugnan algunos músicos latinoamericanos o residentes en esta región. Por ello, la acotada producción de concierto de Julián Bautista en Argentina puede leerse internamente como un testimonio sonoro del proceso de adaptación del músico al medio que lo acoge, a la vez que su relación con el contexto musical porteño refleja una cierta confluencia en torno a la idea de una modernidad hispanoamericana.

A continuación se propone ahondar en las temáticas y los rasgos estilísticos de este grupo de composiciones, ya que en su análisis ofrece datos relevantes acerca de los caminos que sigue el compositor en su inserción en el medio musical argentino. Posteriormente se aborda el diálogo que establecen esas obras con el entramado musical e ideológico de la época con el fin de apreciar las posibles conexiones con la corriente hispanista y los proyectos de renovación musical en Argentina.

\section{ANTECEDENTES: LA ETAPA MADRILEÑA}

El inicio de la carrera compositiva de Julián Bautista está ligado a sus estudios de armonía y composición en la clase de Conrado del Campo en el Conservatorio de Madrid y a su desarrollo en el ambiente artístico-musical de la capital de España en la década de $1920^{2}$. De su maestro recibe una formación académica ligada al tardorromanticismo y, posiblemente, su preocupación por el desarrollo de la armonía cromática. Sin embargo, la reconocida tendencia germanófila de Del Campo no parece tener una repercusión directa en Bautista, quien desde sus comienzos asume una línea de trabajo más ligada a la música francesa, tal como sucede con la mayoría de los jóvenes compositores madrileños de la época. En este sentido, María Palacios, en su estudio de la música madrileña entre 1923 y 1931, considera que su obra para piano Colores (1922) es la más debussista de este período, o que sus Tres

2 Es muy probable que Bautista coincidiera en clase o conociera al compositor chileno Domingo Santa Cruz Wilson (1899-1987), quien estudió con Conrado del Campo durante su estancia en Madrid entre 1922 y 1923. 
preludios japoneses (1927) para orquesta son claramente impresionistas. Pero, como también expone Palacios, esta cercanía al debussismo no es excluyente, ya que en su ballet Juerga (1921) Bautista se acerca a las propuestas de otros dos compositores con gran ascendencia en el ambiente musical madrileño, como son Manuel de Falla, de quien sigue la ideación general del ballet, e Igor Stravinski, del que toma (en algunos números) la idea rítmicomotórica (Palacios 2008: 291, 458, 468).

La década de 1930 comienza para Bautista con la repercusión del estreno de Juerga, la realización de la música para el filme El embrujo de Sevilla (1931), dirigida por Benito Perojo, y su participación en la presentación del Grupo de los Ocho o Grupo de Madrid en noviembre de 1930. En este grupo de jóvenes compositores, que se manifestaban en defensa de la "música moderna”, participaban, además de Bautista, Gustavo Pittaluga (quien tuvo a cargo la conferencia-concierto de presentación), Fernando Remachas, Salvador Bacarisse, Rodolfo y Ernesto Halffter, Rosa García Ascott y Juan José Mantecón. Quizás el contacto con compositores directamente guiados por Falla, como Ernesto Halffter o García Ascott, o la percepción de los cambios estéticos que se estaban dando en su entorno hacen que Bautista se acerque en las composiciones de esta década al neoclasicismo siguiendo la línea de Ravel o del mismo Falla ${ }^{3}$. Entre las obras que se conservan de esta época, quizás, la Suite all'antica, op. 11 (1932, revisada en 1938) y la Segunda sonata concertata a quatro (1938) constituyen la muestra más acabada de este nuevo lenguaje. Respecto de la versión de 1938 de la primera de estas obras Rodolfo Halffter escribe:

La nueva y definitiva versión, en que el aparato orquestal aparece notablemente, reducido, es un modelo de concisión donde solo se conserva lo absolutamente indispensable y, por tanto, de claridad y transparencia, características seculares de la escuela española. El lenguaje neoclásico, cuyo vocabulario es análogo al usado por Falla en "El retablo de Maese Pedro" y en el "Concierto", está empleado con audacia y ejemplar precisión (Halffter 1938: 17).

Por su parte, Christiane Heine, en su trabajo pertinente al pensamiento armónico de Bautista, llama la atención la coincidencia temporal en la realización, en 1934-1935, de su Estudio comparativo de los principales Tratados de Armonía a partir de Jean-Philippe Rameau (posiblemente con motivo de las oposiciones a la cátedra de Armonía del Conservatorio Nacional de Música y Declamación de Madrid que gana en 1936) y la revisión de la suite. En este sentido, la autora considera que:

El material sonoro de la Suite all'antica es diatónico en correspondencia con el sistema heptatónico, y se define mediante la armadura respectiva la supuesta tonalidad de cada uno de los cuatro movimientos, los cuales están relacionados entre sí por parentesco de tercera y quinta, conforme a la tradición clásico-romántica. No obstante, desde el inicio de la obra, queda patente la voluntad del compositor de debilitar la noción tonal, al mitigarse o, incluso, suspenderse las funciones armónicas [... . (Heine 2013: 341-342).

3 Al igual que Palacios (2008: 173-200), Ruth Piquer expone el proceso por el que la crítica musical y los compositores (donde aparecen figuras tan destacadas como José Ortega y Gasset, Manuel de Falla o Adolfo Salazar, entre otros) comienzan, en la década de 1910, a definir en escritos y obras lo que debe ser la música moderna o música nueva. Este proceso consigue cristalizar, a mediados de la década de 1920, la idea de un sentido moderno de nacionalismo cuyos referentes eran Manuel de Falla, Oscar Esplá y las corrientes europeas, francesa (Debussy y Ravel) y rusa (Stravinski y el Grupo de los Cinco). El convencimiento de esta modernidad española es la que va a compartir el Grupo de los Ocho (Piquer 2011: 171-176). 
Como se podrá apreciar más adelante, estos principios estarán presentes en las obras posteriores de Bautista, lo mismo que su preocupación por la enseñanza de la armonía. En este sentido, en su etapa argentina el compositor seguía preguntándose "¿cómo es posible negar la conveniencia de un conocimiento profundo de la armonía clásica, fuente de todas las armonías actuales, aún las más modernas y complicadas?” (Bautista en Ginastera 1961: snp).

Coincidiendo con la revisión de la Suite all'antica, el compositor madrileño retoma la temática hispanista o más puntualmente andalucista en Tres ciudades (1937), composición para voz, piano y orquesta, con textos de Federico García Lorca a quien está dedicada. Estrenada en los Festivales de la Sociedad Internacional de Música Contemporánea en Londres en junio de 1938, es, prácticamente, la única obra con referencias a la música popular española de esta década y constituye una manifestación directa de la repercusión que tiene en este autor el asesinato del poeta granadino. Es necesario recordar aquí que Bautista, al igual que la mayoría de sus compañeros del Grupo de los Ocho, estuvo relacionado con los ideales y las instituciones de la República e incluso una vez iniciada la Guerra Civil asumió diferentes responsabilidades relacionadas con la organización y la educación musical.

\section{LAS COMPOSICIONES DE LA DÉCADA DE LOS CUARENTA}

Julián Bautista arriba a Buenos Aires en 1940 procedente de Bélgica, donde había llegado para recibir el Primer Premio del "Concurs International de Composition Musicale" organizado por el Quatour Belge à Clavier, luego de estar "internado", huyendo del gobierno de Franco, en el "centro especial" para acoger refugiados de Saint-Cyprien, en el sureste de Francia. A pesar de las dificultades que encontraban los exiliados republicanos para establecer su residencia en Argentina, el compositor obtuvo su visado de trabajo relativamente pronto, gracias a la ayuda de Alberto Aguirre y Natalio Botana ${ }^{4}$. En agosto de 1940, en un concierto del Grupo Renovación ${ }^{5}$, se interpreta su Sonatina-Trio para violín, viola y violonchelo compuesta en 1924 y realizada en homenaje a Doménico Scarlatti. Al año siguiente, como director de la orquesta de radio El Mundo, ofrece un concierto de música española para la Sociedad Wagneriana en el que incluye su obra Tres ciudades. En 1943 Juan José Castro estrena en el Teatro Colón la Suite de Danzas de Juerga. Recordemos que este ballet fue compuesto en 1921, estrenado en 1929 y luego revisado por el autor introduciendo nuevos números y modificando la orquestación; para esta versión de concierto extrae tres números de la obra original: "Entrada de los juerguistas", "Tango y zapateado" y "Danza general".

Al mismo tiempo Bautista comienza su participación en las producciones cinematográficas argentinas, campo en el que tenía experiencia tanto por El embrujo de Sevilla como por su previa actividad de pianista musicalizando películas mudas en algunos cines de Madrid. Entre 1941 y 1945 compone la música para casi una veintena de películas, como Canción

4 De Persia 2004: 62. Es necesario recordar que Aguirre era en aquellos años el director de radio El Mundo y Botana, como fundador y director del diario Crítica, era una de las personas más influyentes en el ambiente político-cultural de Buenos Aires.

5 El Grupo Renovación se constituyó en 1929 y se mantuvo activo hasta 1944. Los miembros fundadores fueron José María Castro, Juan José Castro, Juan Carlos Paz, Jacobo Ficher y Gilardo Gilardi. En 1931 se incorporan Luis Gianneo, Honorio Siccardi, Alfredo Pinto y Julio Perceval, y en 1941 Washington Castro. Sin embargo, como indica Scarabino (2000: 79-81), en 1933, por diferentes motivos, se van a producir las deserciones de Gilardi, Pinto, Perceval y Juan José Castro y en 1937 la de Juan Carlos Paz que funda la Agrupación Nueva Música. Véase Ogas 2010: 50-67. 
de cuna (1941, dirigida por Gregorio Martínez Sierra), Concierto de almas (1942, dirigida por Alberto de Zavalía), Mi cielo de Andalucía (1942, dirigida por Salvador Valverde Calvo), Cenizas al viento (1942, dirigida por Luis Saslavsky), Cuando florezca el naranjo (1943, dirigida por Alberto de Zavalía), Los hombres las prefieren viudas (1943, dirigida por Gregorio Martínez Sierra), Juvenillas (1943, dirigida por Augusto Cesar Vatteone), Casa de muñecas (1943, dirigida por Ernesto Arancibia), Nuestra Natacha (1944, dirigida por Julio Saraceni), La dama duende (1945, dirigida por Luis Saslavsky), La fruta mordida (1945, dirigida por Jacques Rémy), entre otras. Esta actividad le va a proporcionar varios premios por parte de la Academia de Artes y Ciencias Cinematográficas de la Argentina (Cuando florezca el naranjo dirigida por Alberto de Zavalía -1943- y Cuando la primavera se equivoca dirigida por Mario Soficci -1944-) y de la Asociación de Cronistas de la Argentina (por La dama duende en 1945, De Persia 2004: 105). En 1944 es nombrado miembro de la Academia de Artes y Ciencias Cinematográficas de la Argentina.

Entre 1944 y 1946 Bautista retoma la composición de música de concierto con la realización de La dama duende, una suite extraída de la música para el filme homónimo, la Fantasía española op. 17 para clarinete y orquesta, y los Catro poemas galegos para voz, flauta, oboe, clarinete, viola, violoncello y arpa. La Fantasía española fue compuesta entre 1944 y 1945, está dedicada al reconocido clarinetista belga Maurice van Guchte (1897-1953) que en esos años es profesor de clarinete y saxofón en el Real Conservatorio de Música de Gante. Es la obra de concierto de mayor aliento de esta década y ya desde su nombre anuncia la intencionalidad del compositor de abordar una temática hispanista, algo que se constata en la partitura con la presencia de algunos tópicos de esta música, como son los ritmos y estructuras fraseológicas ligados a danzas tradicionales, entonación melismática, giros modales, fuerte expresividad e imágenes sonoras sugerentes.

Esta Fantasía expone un plan formal de cuatro secciones y en la primera de ellas, de una extensión de 89 compases, se presentan los dos materiales temáticos principales de la obra. En las restantes se producen diferentes elaboraciones o desarrollos de esas ideas incluyendo una cadencia a cargo del instrumento solista en el cierre de la tercera sección. El primero de esos materiales es presentado por los fagotes (cc. 1 al 8), está en un compás de $3 / 8$ y se caracteriza por el empleo de la figuración rítmica de la jota ${ }^{6}$ (ver Ejemplo 1 ).

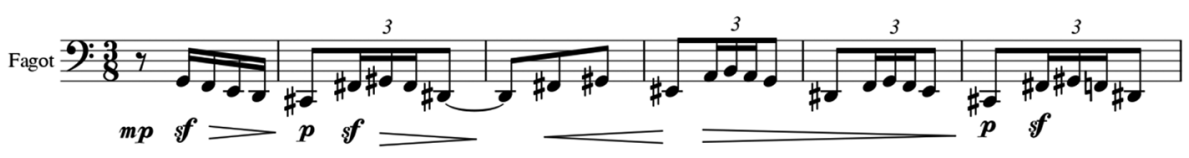

Ejemplo 1: Fantasía española op. 17, cc. 1-6.

6 Si bien en varios cancioneros y trabajos pertinentes al folclor español aparece la figuración corchea, tresillos de semicorcheas, corchea en melodías y acompañamientos (por ejemplo, en Torralba 1982: 41), aquí la tomamos teniendo en cuenta el empleo del mismo por parte de los compositores académicos en sus jotas. Así se puede apreciar, por ejemplo, en la conocida "Jota" de las 7 Canciones Populares de Manuel de Falla (véase cc. 17-32, sus repeticiones y elaboraciones), en la "Jota" de Introducción y Capricho Jota de Pablo de Sarasate (cc. 102-124) o en la conocida Jota Aragonesa op. 64 de Camille Saint-Säens (cc. 72-86, 156-173 o 209-207), solo por nombrar algunos de los innumerables casos donde este esquema rítmico es empleado para aludir a este género popular. 
La segunda idea temática tiene como particularidad que es presentada por el clarinete, sucesivamente, en dos elaboraciones bastante diferentes. Aunque no es difícil apreciar que ambas comparten la relación melódica estructural basada en el descenso cromático del segundo grado (re\#) al primero (do\#); los ascensos en valores breves por grados conjuntos y los descensos en valores de mayor duración con terceras quebradas; reiteradas ornamentaciones sobre un sonido de referencia; y la presencia del tetracordio frigio en la configuración de los diseños melódicos. Estas diferencias van a adquirir relevancia en el desarrollo global de la obra, por lo que es necesario diferenciarlas como se aprecia en el esquema de la figura 1, donde la primera presentación aparece como "b" y la segunda como "c"7 (ver Ejemplos 2 y 3, y Figura 1).

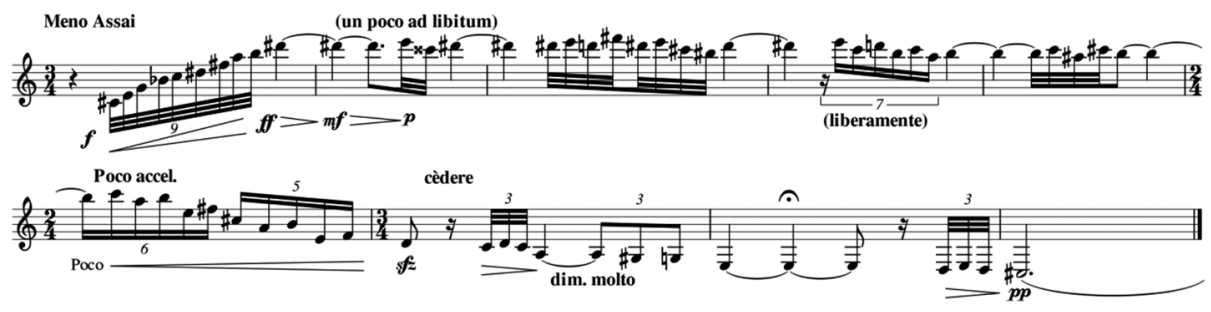

Ejemplo 2: Fantasía española op. 178, cc. 36-45 (extracto parte del clarinete).
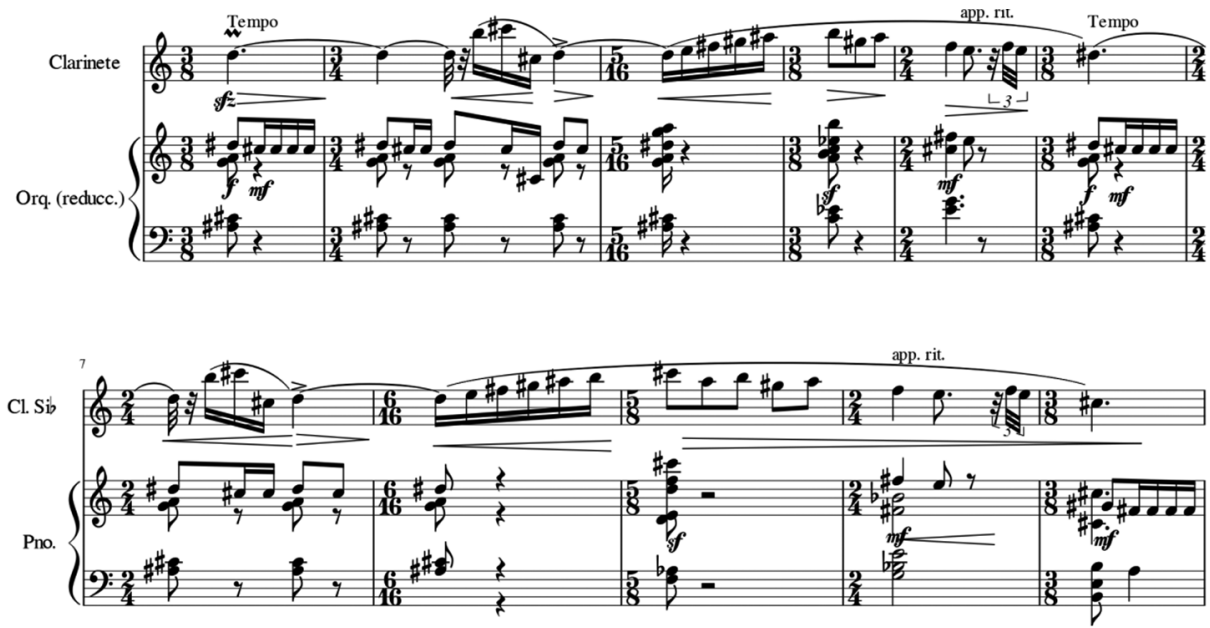

Ejemplo 3: Fantasía española op. 17, cc. 48-58.

7 En la Figura 1 no se diferencian la aparición de cada uno de los temas para no recargar el esquema, pero se debe tener en cuenta de que en cada nueva aparición los materiales temáticos sufren transformaciones y combinaciones.

8 La parte original de clarinete en si bemol está escrita aquí en su tonalidad de efecto (notas reales). 
Temas
Plan tonal
cc.
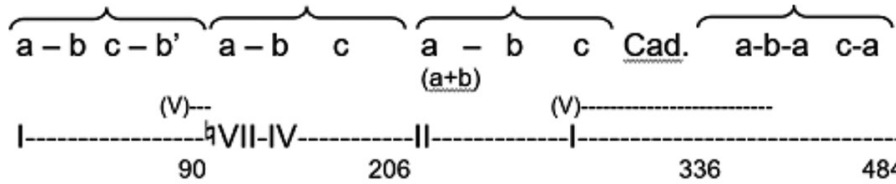

$(a+b)$

(V)--

336

Figura 1: Fantasía española op. 17, esquema formal.

Como se puede apreciar en el esquema precedente, formalmente la obra responde al principio de transformaciones temáticas, teniendo su punto de tensión estructural en la cadencia del instrumento solista que coincide con el retorno a la tónica, aunque por medio de una extensa función de dominante. Dentro de esta, en principio, claridad tonal-formal Bautista desarrolla un tratamiento armónico y de organización de alturas claramente marcado por los principios neotonales de las corrientes compositivas de las primeras décadas del siglo XX. Un ejemplo de esto se encuentra ya en la primera sección donde "a" y "b" se complementan para la centralización de la tónica principal de la obra, do\#, mientras "c" y la repetición de "b" son divergentes en cuanto conducen a una semicadencia y posterior progresión modulante al VII grado descendido.

También en necesario hacer notar que en ese proceso de centralización tonal inicial existen divergencias internas que se pueden relacionar con el concepto de bitonalidad, como lo entendía Manuel de Falla. Por ejemplo, en el comienzo de la obra, aunque la altura de referencia tonal es el do\# aparecen diseños que se pueden relacionar con la escala de do mayor. Así se puede apreciar en el descenso inicial al do\# que da lugar al tetracordio de la escala diatónico-cromática española o escala española; en la superposición de los compases 4 y 5 ; y entre el compás 17 y el compás 21 (ver Ejemplo 4) cuando el material inicial se despliega sobre una escala sin alteraciones sobre el quinto grado de do\#. Este recurso se hace presente en diferentes momentos y regiones tonales de la obra erigiéndose en un rasgo estilístico destacado.

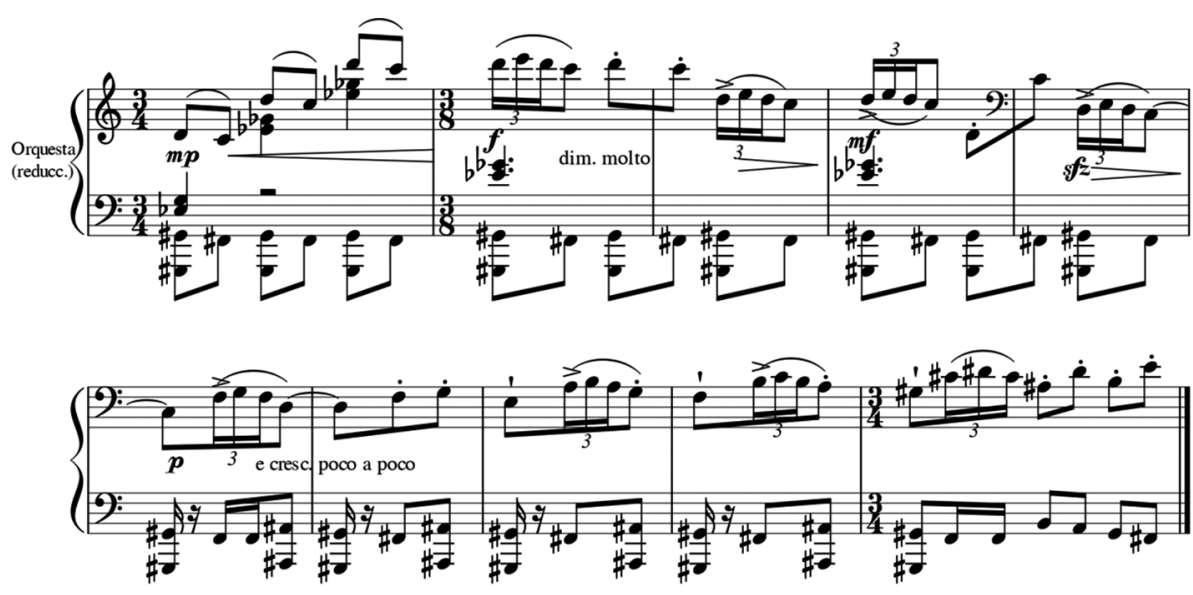

Ejemplo 4: Fantasía española op. 17, cc. 13-21. 
Una variante de este recurso, aunque ahora mediante un enlace armónico más complejo, se da en la presentación de "c". En este caso (cc. 49-54) melódicamente se marca el sonido re\# (con un descenso en modo frigio hacia este sonido) con una armonía de sexto grado (acorde de la \# con séptima, octava disminuidas y la cuarta por la quinta). Estructuralmente, esta armonía sobre el sexto grado es una bordadura del acorde de tónica en el que resuelve el primer grupo temático (c. 45) y el que aparece en tercera inversión en el compás 59 como reposo momentáneo de "c". A pesar de que el sexto grado no tiene un valor estructural en este pasaje, Bautista enfatiza su aparición con el movimiento paralelo de acordes por cuartas que le precede y con el acento tónico de quinta disminuida en el bajo que coincide con el cierre del motivo inicial de "c" (ver Figura 2).

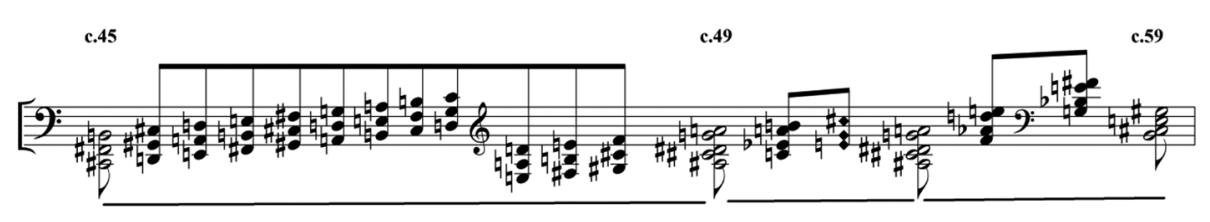

Figura 2: Fantasía española op. 17, esquema armónico cc. 45-59.

La prolongación de una función, el empleo de movimientos paralelos de acordes con diferentes estructuras para enmascarar un enlace armónico y las notas agregadas o la superposición de estructuras acórdicas también son de uso frecuente en el lenguaje del compositor. Un pasaje de mayor aliento donde se combinan estos recursos es el comprendido entre los c. 147 y 182. Aquí, luego de establecer la modulación al cuarto grado, se prolonga esta armonía coincidiendo con el sistema axial indicado por Ernő Lendvai para la música de Bèla Bartók (Lendvai 2003: 11-26), de forma que esa prolongación describe una relación entre las armonías de fa\#-la - do-mib-fa\#, utilizando entre cada una de ellas acordes bordaduras o de paso como se puede apreciar en el diagrama (ver Figura 3). En esta prolongación predominan las estructuras de acordes de séptima de dominante y hay que destacar que las armonías se pueden agrupar por pares a distancia de quinta disminuida si se tiene en cuenta el material temático que se desarrolla en ellas; "b" sobre fa\# y do, y "c" sobre la y mib. También se puede inferir que esta extensión del cuarto grado de la tonalidad principal prepara y enlaza con la modulación a la región del segundo grado del compás 206.

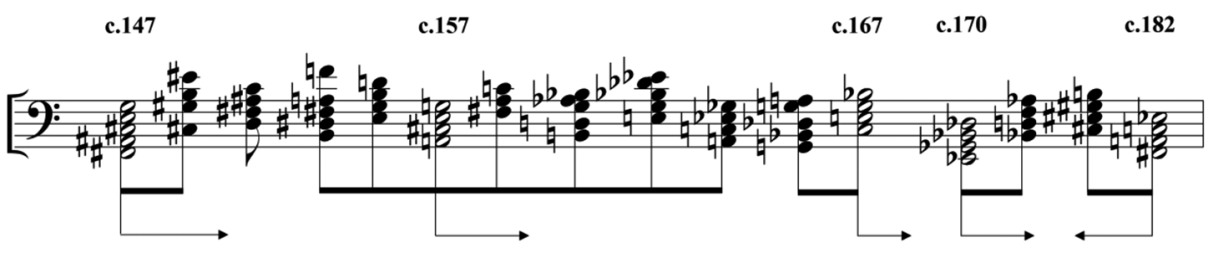

Figura 3: Fantasía española op. 17, esquema armónico cc. 147-182. 
A partir de estos ejemplos es posible advertir la presencia de un planteamiento armónico y de organización de alturas que tienden a enmascarar o dar cierta laxitud a la clara estructuración tonal (ligada a la tradición clásico-romántica) en la que está anclado el discurso de la obra. Por correlación, algo semejante sucede con la forma musical, las cuatro secciones que se indican en el esquema son una manera de materializar una estructura cerrada (es posible interpretar la primera y la última sección como exposición y recapitulación) con la ubicación del clímax o tensión máxima de la obra en el tránsito entre el segundo y tercer tercio de la misma (sección áurea).

La obra inmediatamente posterior a la Fantasía es Catro poemas galegos; realizados sobre poemas de Lorenzo Varela, quien los escribió a partir de grabados de Luis Seoane. Esta composición significa un importante hito en la música galleguista, ya que por primera vez se aborda esta temática desde los postulados estilísticos del neoclasicismo del Grupo de los Ocho. Las cuatro canciones que conforman la obra para voz, flauta, oboe, clarinete, viola, violonchelo y arpa, son "María Pita", "O touro. Na proba d'obispo Adaulfo", "O Ruy Xordo” y "María Balteria”. Las poesías de Varela están escritas en gallego y Bautista recurre a una sonoridad arcaizante, que parte de la propia selección del conjunto instrumental y se consolida con un destacado tratamiento modal y cierta flexibilidad métrico-rítmica. Estos aspectos se aprecian ya en la primera de las canciones, "María Pita", que se estructura en tres secciones conformadas cada una de ellas por un primer pasaje instrumental y luego por la parte cantada de cada una de las estrofas de la poesía. El compositor solo introduce una modificación a la poesía, después de los versos 18 (“din as miñas campanas, escoitade") y 20 ("de monte a monte e mais de ría a ría:") agrega unas sílabas onomatopéyicas relacionadas con el repique de las campanas ("din, don, din, don”) (García López 2015: 98).

En el plano estructural, todos los pasajes instrumentales presentan una relación V-I de mi bemol con final en un sexto grado mayor. En la segunda sección esta relación de acordes aparece precedida por una semejante en sol bemol y tanto la segunda aparición como la tercera de este pasaje instrumental son más extensas y presentan un tratamiento escalístico sobre do mayor que anticipa el sexto grado. Ahora bien, esos segmentos instrumentales introducen las partes cantadas que, siempre en el plano estructural, se desarrollan a partir de una organización de alturas con tónica fa, predominando el modo dórico, aunque en los cierres (dos últimos versos de cada estrofa) tienden hacia el modo eólico.

En relación con la sintaxis armónica de esta primera canción, es posible apuntar que el recurso de acordes a distancia de quinta mencionado, se repite varias veces como acompañamiento de la parte cantada (relación en el bajo mib - sib o sib - fa), aunque con algunas variantes en la construcción de las estructuras verticales. También se puede apreciar un claro tetracordio frigio en el bajo de comienzo de la parte cantada tanto en la primera como en la segunda sección (A - A'), junto con el movimiento de quintas y cuartas paralelas. Por su parte el recurso de superponer una secuencia armónica de V- I de mi bemol y desarrollar en la voz superior una escala de do mayor, nos retrotrae a lo comentado referente al recurso bimodal en esta generación de compositores españoles. Este recurso vuelve a aparecer en la segunda canción, "O touro. Na proba d'obispo Adaulfo", aunque con una particularidad, ahora la estructura vertical sobre sol, que ha sido tonicalizado en los primeros tres compases, es por quintas (sol-re-la) y en ella se desarrolla una escala de mi bemol dórico. Este tratamiento tonal-modal, con su consiguiente incidencia en la organización de alturas y las estructuras verticales, es semejante en el resto de las canciones (ver Ejemplo 5). 

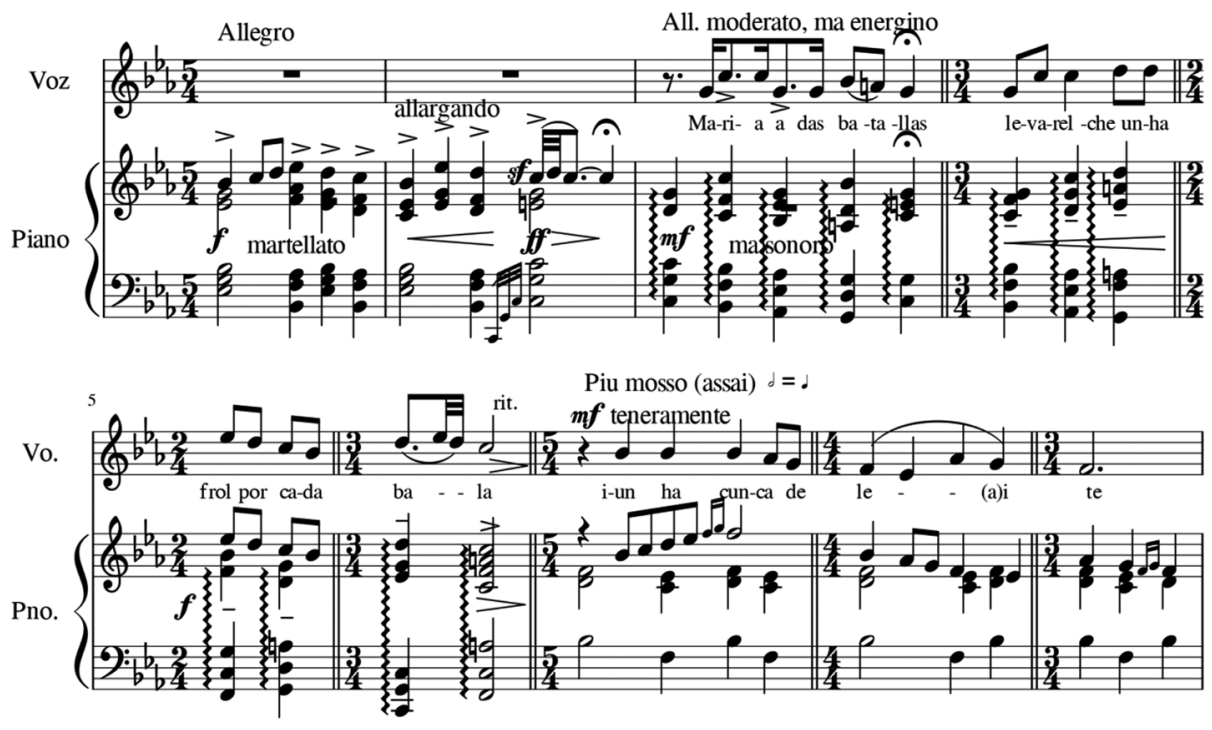

Ejemplo 5: Catro poemas galegos, "María Pita”, cc. 1-9.

Por su parte, el tratamiento rítmico de la voz es otro de los factores que refuerzan el aspecto arcaizante o retorno a una música medieval buscado por el compositor. Para ello reitera motivos melódico-rítmicos con sutiles variaciones en cada nueva presentación, lo que le permite resaltar la acentuación y la flexibilidad rítmica de los versos. En "O Ruy Xordo", por ejemplo, la unidad de tiempo es siempre la negra y las variaciones motívicas van a estar directamente ligadas a la acentuación de los endecasílabos que conforman cada estrofa. En las dos primeras estrofas se puede apreciar la acción del compositor en el poema, con las variaciones de la extensión musical de los versos y la reagrupación que hace de los mismos.

Esas dos estrofas expresan:

Aramos sobre os mortos nesta terra

i o noso pan ten un sabor de ósos

familiares, irmáns. O monte berra

baixo do arado, e chámannos os nosos,

desde a morte con voces conocidas:

«Nin marqueses, nin cregos, nin doutores

fixeron as ribeiras verdecidas,

nin o guerreiro coiro dos tambores.

De acuerdo con la acentuación presentada en la canción, los versos primero y séptimo son heroicos puros (acentos en la $2^{\mathrm{a}}, 6^{\mathrm{a}}$ y $10^{\mathrm{a}}$ sílabas), el tercero y el quinto son melódicos puros (acentos en la $3^{\mathrm{a}}, 6^{\mathrm{a}}$ y $10^{\mathrm{a}}$ sílabas), los dos últimos de cada estrofa son sáficos puro y corto, respectivamente (acentos en la $4^{\mathrm{a}}, 6^{\mathrm{a}} / 8^{\mathrm{a}}$ y $10^{\mathrm{a}}$ sílabas), y solo el segundo verso (con acentuación en la $5^{\mathrm{a}}$ y $10^{\mathrm{a}}$ sílaba) se puede asociar al galaico antiguo. Además, en el aspecto formal, Bautista ubica el interludio instrumental entre el primer y segundo verso de la segunda estrofa. Así, el compositor evidencia su interpretación del contenido del lenguaje 
verbal, tanto en el ritmo que imprime a las palabras como en una estructura formal diferente a la de la poesía (ver Ejemplo 6).

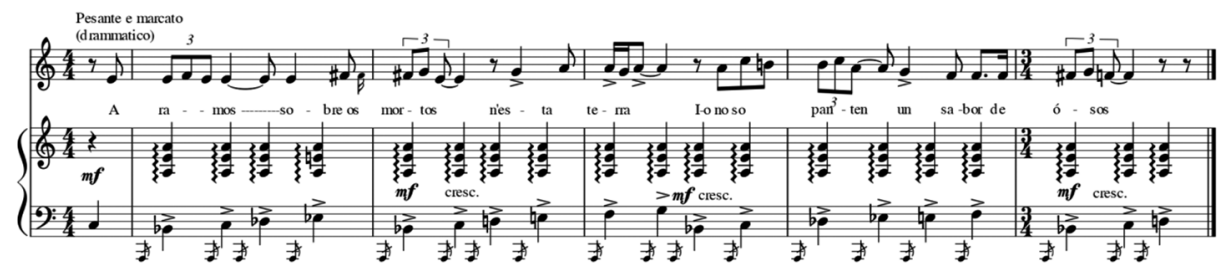

Ejemplo 6: Catro poemas galegos, "O Ruy Xordo", cc. 9-13.

\section{LAS COMPOSICIONES DE LA DÉCADA DE LOS CINCUENTA}

El Romance del Rey Rodrigo, para coro mixto, es la última obra de concierto con temática hispanista compuesta por Bautista. La termina de componer en julio de $1956^{9}$, es decir, una década después de los Catro poemas galegos. El texto poético para este romance es, según consta en la portada de la partitura, "extraído del 'Romancero español' adaptado y ordenado" por el compositor. Está formado por seis partes: "Imprecación", "La profecía", "Imprecación", "La carta", "Imprecación" y "La traición". La adaptación del romance realizada por Bautista para esta composición ha permitido lecturas ligadas a su antifranquismo. Evidentemente, la presencia en el romance de la figura del traidor, culpable de que España sea abrasada por los enemigos, o las lamentaciones que aparecen en su texto, “¡Ay de ti, madre España! ¡Ay de ti, la mal guarnida!”, dan pie a realizar esas asociaciones con la situación española de la época. Más si se tiene en cuenta que la España franquista pocos meses antes de esta composición (el 14 de diciembre de 1955) consigue ingresar en la ONU como país miembro, con lo que el gobierno republicano en el exilio comienza a perder la poca influencia que aún tenía.

Musicalmente presenta características similares a las obras anteriores, aunque, en líneas generales, la conformación de las estructuras verticales y de las relaciones armónico- funcionales se presentan con rasgos más diáfanos. Destaca, como en los poemas, la elaboración y transformación motívica, especialmente en el tratamiento del motivo inicial de la "Imprecación" (donde se expresa el primer verso, "Madre España") que se manifiesta en diferentes momentos de la partitura como factor de unidad estructural y significante. En este sentido, se pueden apreciar repeticiones y transformaciones del mismo como en el tercer verso de la "Imprecación" (cc. 16-17), que se cierra con el motivo junto con la palabra "traidor"; en "La profecía", cuando los versos describen que las cincuenta doncellas cantan dentro de la tienda; o en "La traición", donde este motivo tiene un importante protagonismo, como, por ejemplo, se aprecia en los versos “iAy de ti madre España/por un perverso traidor/ toda eres abrasada", en el inicio de los versos " $\mathrm{OOh}$, dolor sobre manera!/;Oh, cosa nunca cuitada! y en la primera parte de los versos "España sea domeñada/ y perdido el Rey señor" (ver Ejemplo 7).

9 Nota al pie de la partitura. 


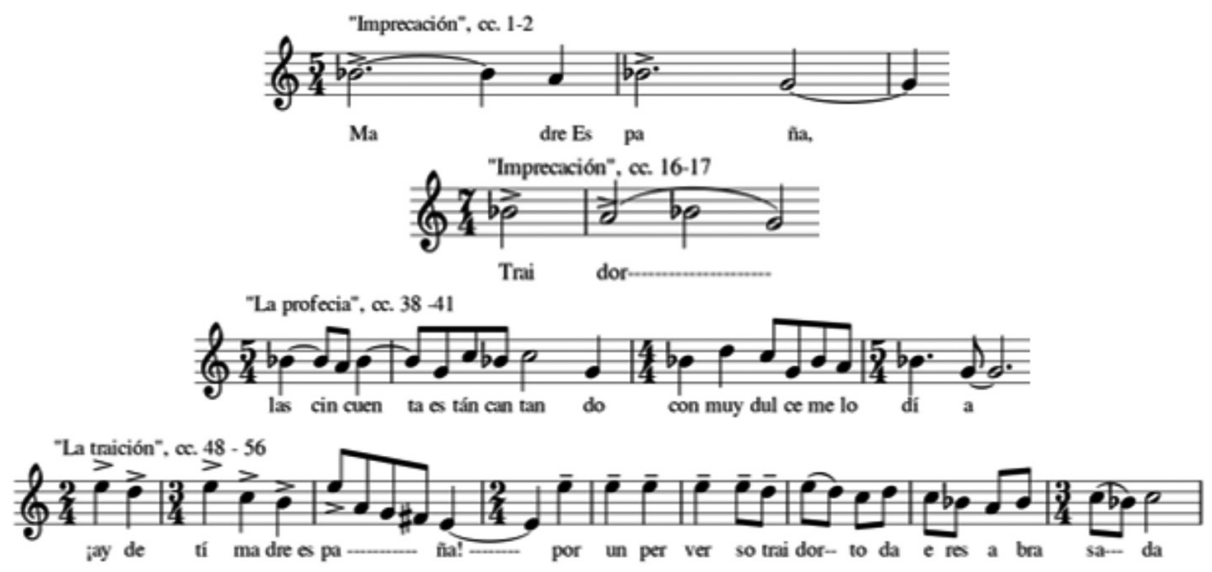

Ejemplo 7: Romance del Rey Rodrigo, ejemplo de transformación motívica.

En la década que separa a las últimas dos obras, Julián Bautista compuso música para más de dos decenas de películas. En ellas continúa la colaboración con directores como Ernesto Arancibia (Mirad los lirios del campo, 1947; María de los Ángeles, 1948) o Mario Soffici (Celos, 1947; La barca sin pescador, 1950) y comienza su relación artística con otros, como Carlos Hugo Christensen (Si muero antes de despertar, 1952; No abras nunca esa puerta, 1952; Un ángel sin pudor, 1953; Armiño negro, 1953), León Klimovsky (Suburbio, 1951; El pendiente, 1951), Carlos Schlieper (Por ellos... todo, 1948; Fascinación, 1949; Los árboles mueren de pie, 1951) o Hugo Fregonese (Apenas un delincuente, 1949). También coincide nuevamente con escritores exiliados que tienen a cargo los guiones de algunas películas, como es el caso de Rafael Alberti y Tania León (El gran amor de Bécquer, 1946) o Alejandro Casona (La barca sin pescador, Los árboles mueren de pie, Si muero antes de despertar, No abras nunca esa puerta, Un ángel sin pudor). En este ámbito, una producción de características particulares es Pupila al viento (1949), cortometraje realizado por Enrico Gras y Danilo Trelles para la Dirección General de Turismo de la República del Uruguay, con "palabras rítmicas” de Rafael Alberti dichas por el autor y María Teresa León. Este trabajo, cuyas imágenes pertenecen a la ciudad de Punta del Este, se basa en una integración plena de las palabras, las imágenes y la música, y es considerado la primera película experimental de Uruguay (De-Marchis/ Hernanz Angulo 2013: 34).

Como ya se señaló, en las restantes composiciones, Sinfonía breve (1956), Segunda sinfonía "Ricordiana" (1957) y el Cuarteto $N^{o} 3$ para instrumentos de arco (1958), Bautista se distancia de la temática hispanista. El lenguaje compositivo de estas obras presenta muchas similitudes con lo abordado hasta aquí, aunque también es posible detectar diferencias de cierto calado. En el caso de las sinfonías la estructuración tonal global sigue manteniendo una tónica de referencia en el conjunto de la obra. En este sentido la Sinfonía breve presenta la estructura siguiente: "Allegro bien rítmico" (la) -"Moderato assai ed espressivo" (do \#) - "Allegro vivace" (la); y, por su parte, la relación en la Segunda sinfonía es de "Allegro" (re) -“Andante moderado" (sol)- "Allegro giusto" (re). También en la estructura interna de los movimientos sigue presente la idea de una estructura tonal definida por los principios de la tradición clásico-romántica, junto con un tratamiento armónico y de organización de alturas que, en cierta medida, oculta o hace menos patente 
esas relaciones estructurales. Sin embargo, la no presencia en estas obras de una referencia directa a ritmos o giros melódicos de la música tradicional hispánica hace más evidente el intento de enmascaramiento de las relaciones tonales subyacentes en el diseño de los materiales temáticos.

Un ejemplo de ello se encuentra en el tema inicial del "Allegro bien rítmico" de la Sinfonía breve, donde el gesto cadencial del inicio (cc. 1- 4) es enriquecido/desdibujado con diseños melódicos cromáticos, saltos de quinta disminuida (como el del cierre en el violín) o apoyaturas armónicas. Aunque esto no desvirtúa la percepción del apoyo tonal ni del planteamiento por terceras alternadas que sustenta el material melódico (ver ejemplo 8). También en el primer tema del "Allegro" de la Segunda sinfonía las relaciones de terceras juegan un papel destacado, ya que el mismo se forma a partir del arpegio de una tónica mayor/menor (re-fa-fa\#-la) y esta estructura acórdica se despliega en otros grados (III, \#III, V, etc.).

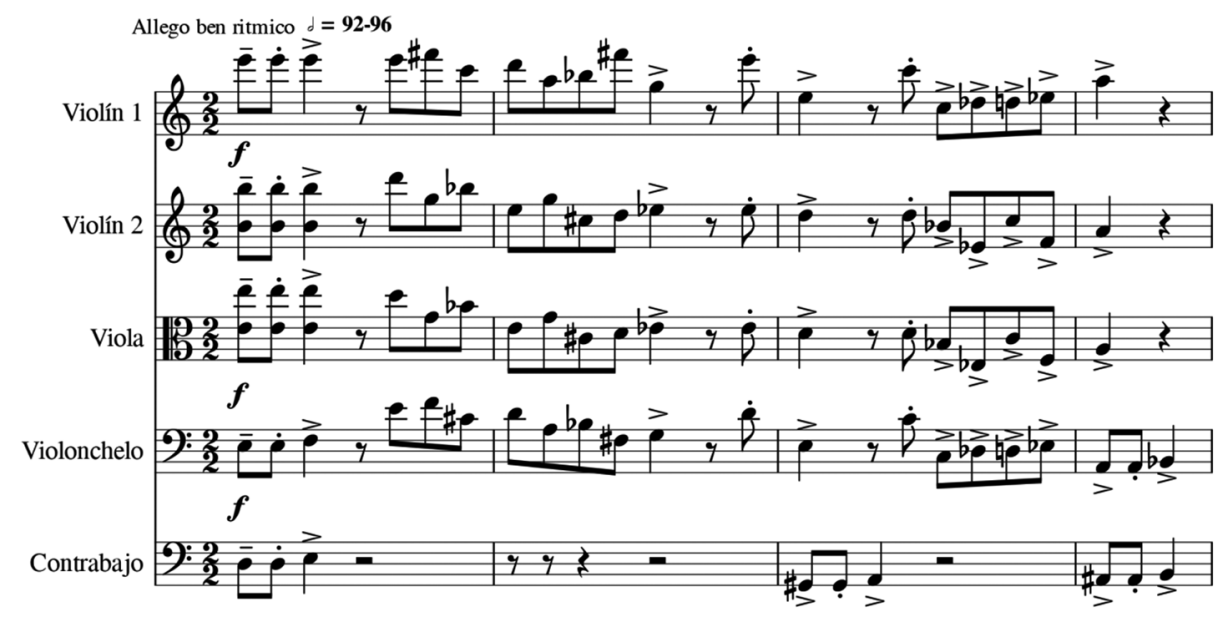

Ejemplo 8: Sinfonía breve, "Allegro ben ritmico", cc. 1- 4 (extracto parte cuerdas).

Un caso diferente de centralización tonal se aprecia en el segundo movimiento, "Moderato assai ed espressivo", de la Sinfonía breve, donde vuelve a aparecer, como en la Fantasía, la superposición do/do\#. Aquí, mientras el gesto tonicalizante del diseño de las cuerdas, que acompaña el solo del fagot, conduce al do\#, el solo de viola se apoya en un acorde de do (primera nota de cada tiempo). Esta cierta inestabilidad tonal tiende a resolverse en el compás 10 con la aparición de un bajo ostinato. Este bajo, que recuerda al ground o el pasacalle, está formado, inicialmente, por los siete sonidos descendentes de la escala de do\# eólico y la repetición de la tónica. Posteriormente, siempre dentro del mismo ámbito, esa escala sufrirá diferentes variaciones en su conformación. La melodía que presenta la flauta entre los compases diez y dieciséis converge con el do\# del bajo y a partir del compás 17, cuando pasa al oboe, tiende a la centralización de la relación sol-do, dando sentido, así, al inciso de la viola presentado en el pasaje inicial (ver Ejemplos 9 y 10). 


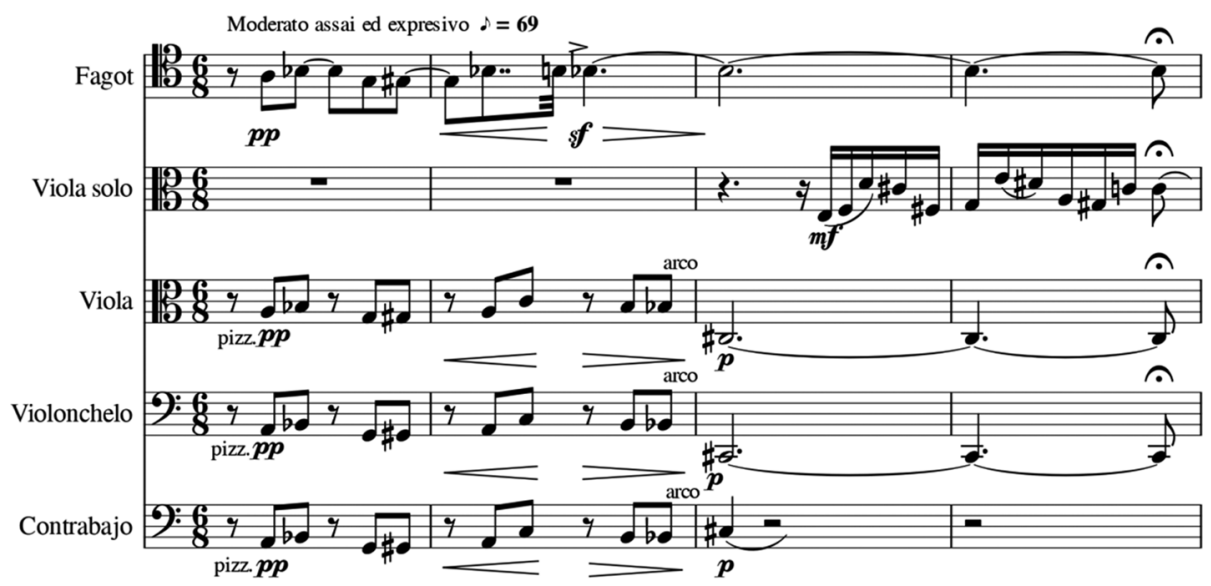

Ejemplo 9: Sinfonía breve, "Moderato assai ed espressivo", cc. 1-4.

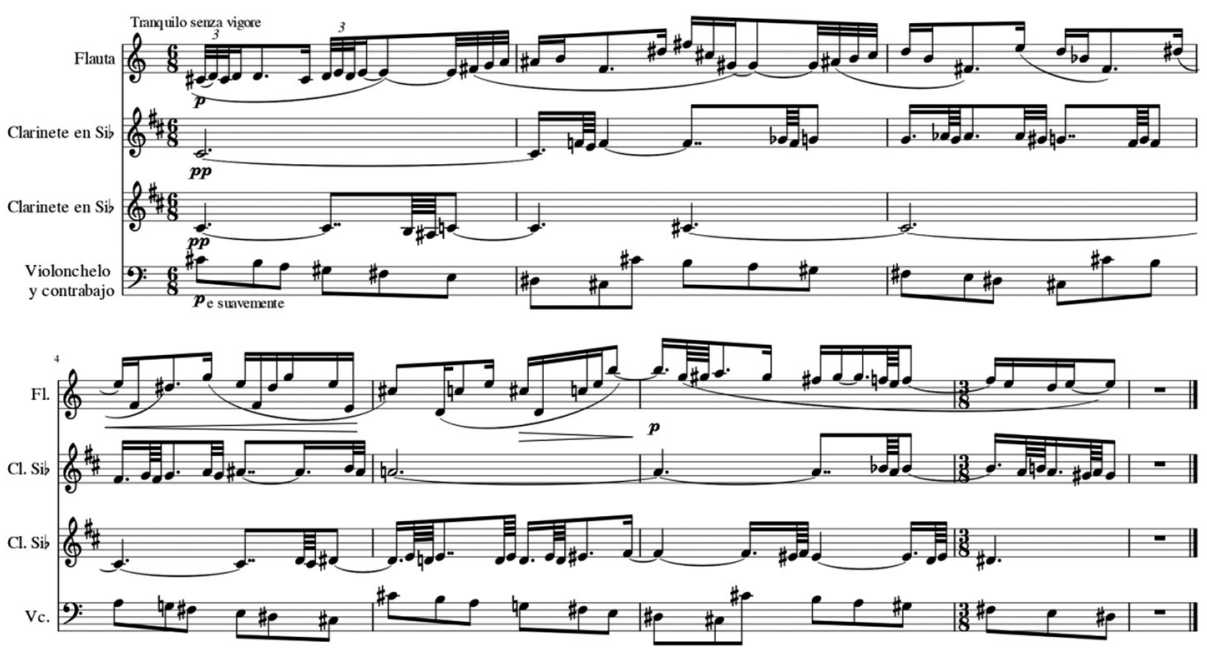

Ejemplo 10: Sinfonía breve, "Moderato assai ed espressivo", cc. 10-16.

En el caso del Cuarteto $N^{\circ} 3$ para instrumentos de arco, Julián Bautista avanza un paso más en la distorsión de las relaciones tonales que rigen su ideación compositiva. En la estructura global del cuarteto llama la atención que, teniendo en cuenta el punto de partida y llegada de los movimientos extremos, el compositor inicia la obra con una centralización del do\#, en el primer movimiento ("Moderato assai e sostenuto"), para concluir con una tonicalización de do, en el último ("Allegro molto deciso"). Por su parte, en el tercer movimiento ("Lento, non troppo") la altura de referencia es el fa y en el segundo solo ("Allegro giusto") en la parte central aparece un pasaje que tiende a do seguido de un pedal figurado de sol. A continuación se prestará atención a los dos primeros 
movimientos o, como se verá, a lo que también se puede considerar como introducción y primer movimiento. Ya que ambos fragmentos permiten ejemplificar más claramente los elementos diferenciadores respecto de las obras anteriores que aparecen en esta.

En contrastes con estos puntos de (posibles) referencias tonales, el compositor suma a su repertorio de estructuras verticales y de organización de alturas divergentes observado en las obras anteriores, la presencia de principios dodecafónicos, especialmente en algunos pasajes del segundo movimiento. La serie con la que se abre este "Allegro giusto" (cc. 1-2) es derivada del motivo inicial del primer movimiento, con el que comparte sus primeros cuatro sonidos y parte del perfil melódico. Luego aparece otra serie (cc. 3-4) que es muy semejante en su perfil melódico a la anterior (misma orientación, diferentes intervalos). En la frase inicial de este segundo movimiento (c-1-10), a la exposición de las dos series (al unísono en los cuatro instrumentos) le sigue la retrogradación de alturas $\mathrm{y}$ valores de estas en sentido inverso a como las expone, es decir: Original x - Original $\mathrm{y}-\mathrm{R}_{3}$ de $\mathrm{y}-\mathrm{R}_{3}$ de $\mathrm{x}$. Esta doble retrogradación se cierra con un pasaje cromático sin control serial (ver ejemplo 11).

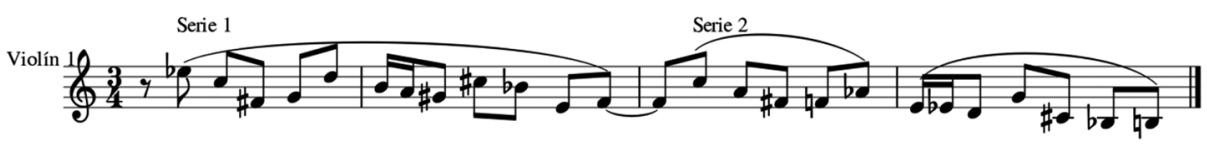

Ejemplo 11: Cuarteto $N^{\circ} 3$, "Allegro giusto", violín 1, presentación de las series.

Por lo expuesto, es posible establecer que la frase inicial del segundo movimiento surge de una variación del tema del primer movimiento. Lo que genera un sólido lazo entre el "Moderato assai e sostenuto" y el "Allegro giusto", a lo que se suma el attaca indicado al final del primero. La idea de relación temática entre ambos movimientos coincide con la propia lógica de la obra, ya que el tema en el primer movimiento es presentado sucesivamente con algunas variaciones y las series también experimentarán transformaciones posteriores. Lo que da lugar a pasajes sobre el total cromático, pero sin organización serial como si se trataran de temas de doce sonidos. Por otra parte, ambos materiales están presente de forma textual en el final del cuarto movimiento y con sustanciales transformaciones en el tercero. Todo ello permite determinar que este cuarteto se corresponde con la idea de obra cíclica.

Pero la similitud apuntada entre los materiales temáticos del primer y segundo movimiento, así como los pasajes donde retoma la idea serial, permiten ahondar en los intricados caminos que Bautista recorre en su búsqueda de una ampliación del concepto de tonalidad y sus consecuencias en el plano formal. A continuación se detallan algunas de estas relaciones:

a) En la presentación temática del primer movimiento, aunque se trata de una melodía de once sonidos que incluye tres saltos de tritono, en los violines el gesto del primer compás cierra con la tercera Re b - fa y el cierre de la semifrase, en el primer tiempo del compás 3, sobre Sol \# - Si. Esto concuerda con la armonía de Do\# 7 sobre la que se presenta este material. Además, siguiendo la lógica tonal, cuando este material es retomado en la última frase del movimiento (c.37-38) aparece transportado a la dominante (ver Ejemplo 12). 


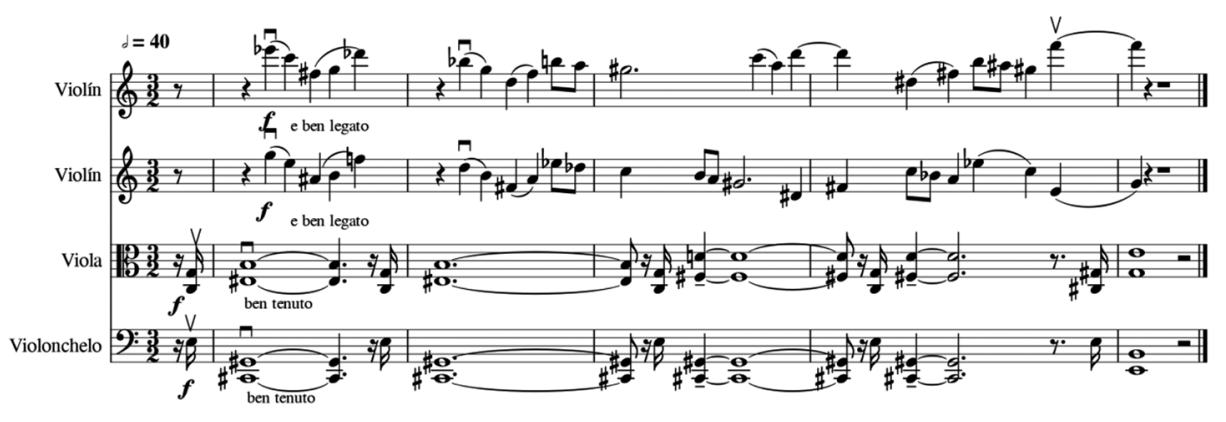

Ejemplo 12: Cuarteto $N^{\circ}$ 3, "Moderato assai e sostenuto", cc. 1-4.

b) A pesar de las series con las que comienza el segundo movimiento, Bautista no deja de dar una referencia tonal, con los acordes tríadas que están presente en los sonidos 1; 2 y 4 de cada serie (Do menor en Ox y Fa mayor en Oy). Este inicio tiene correlación con el cierre sobre un acorde de Do de la segunda frase (c.23), que, a su vez, da pie a la presentación del tema b, ya expuesto en el primer movimiento, aunque aquí adquiere un carácter elaborativo (ver Ejemplo 13).

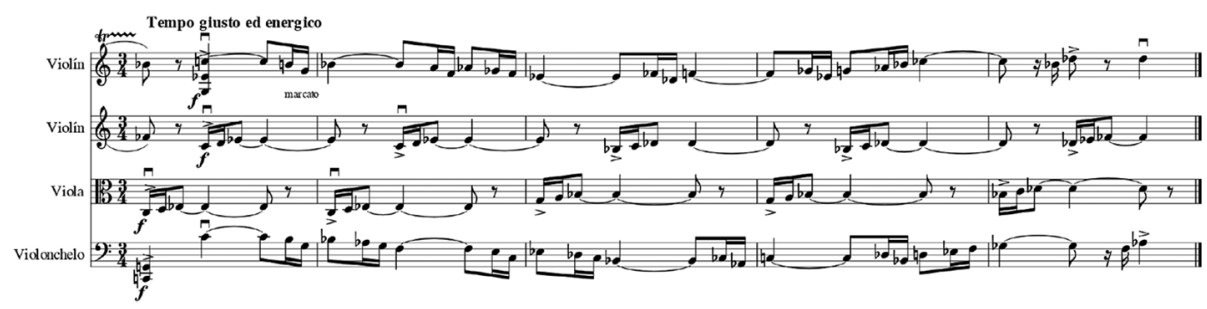

Ejemplo 13: Cuarteto $N^{\circ} 3$, "Allegro giusto", cc. 23-27.

c) También en el "Allegro giusto", en el fragmento elaborativo que va desde el compás 96 al 138 aparece otra expresión de las superposiciones que origina este discurso serial-tonal. Aquí, luego de un pasaje donde en el bajo predominan los arpegios sobre acordes por terceras, se expone la primera de las series en la altura original, seguida de una variación de esta, luego se repite todo transportando siete semitonos. Sin embargo, la exposición del original de la serie $\left(\mathrm{O}_{\mathrm{y}}\right)$ se inicia en una armonía de do y la de $\mathrm{O}_{\mathrm{y} 7}$ en un acorde de sol, algo que prolonga la sonoridad de los compases previos a esta sección y recuerda el planteamiento global del movimiento y de la obra (ver Ejemplo 14). 


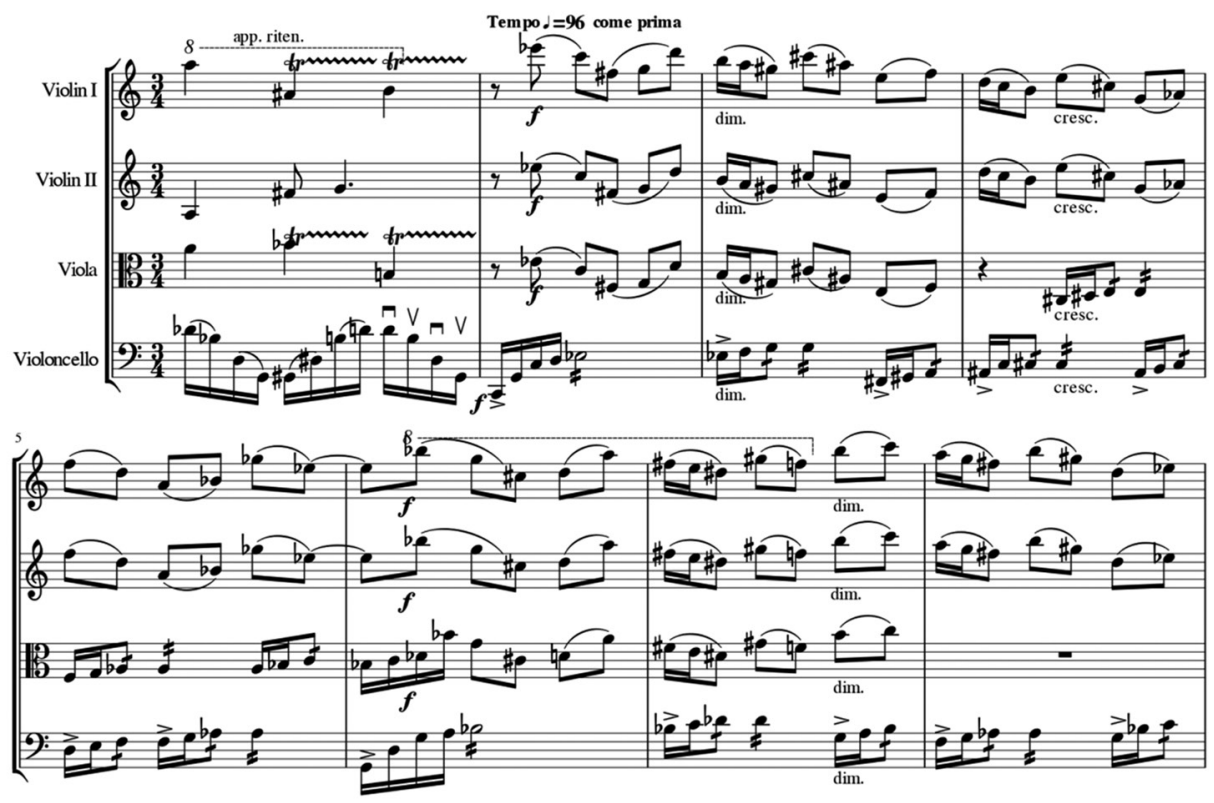

Ejemplo 14: Cuarteto No 3, "Allegro giusto", cc. 95-101.

d) En el final de este segundo movimiento, a la manera de las recapitulaciones tonales, se repite textualmente toda la primera frase que incluye las series, aunque el segundo tema se presenta transportado una quinta por encima de lo que lo hacía en la primera sección.

e) Un último aspecto del lenguaje de este movimiento a destacar es la presencia de un cluster en el cierre del primer movimiento, a continuación de que se escuche, por dos veces, el acorde de sol \# con séptima disminuida y mayor. Algo semejante sucede en el comienzo del tercer movimiento, donde luego del inicio con un acorde tríada de fa mayor se escucha un cluster cromático.

En el gráfico siguiente se resumen las relaciones temáticas y tonales de los dos primeros movimientos. Como se ha indicado, a causa de la relación entre los materiales de ambos movimientos, es más apropiado considerar que en el primero se presentan los temas "a" y "b", y que luego se retoman, con modificaciones, en el segundo. En el plano tonal, según la estructura de estos movimientos y de los posteriores, el do\# y su conducción al sol\# del primero deben ser contemplados como un segundo y un sexto grado descendidos de la tonalidad de referencia de la obra. Siempre teniendo en cuenta que en muchos pasajes este planteamiento estructural ligado a la tonalidad no tiene una correlación directa con la percepción acústica de los mismos (ver Figura 4).

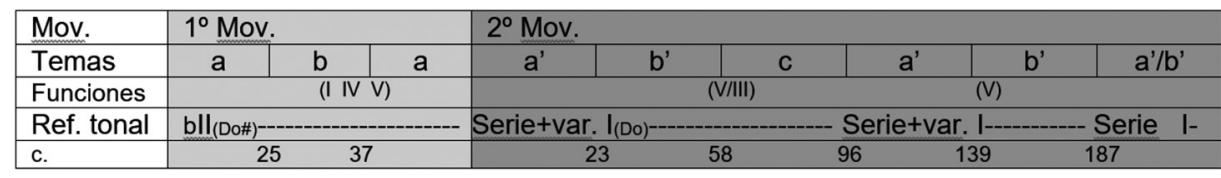

Figura 4: Cuarteto $N^{o} 3$, "Moderato assai e sostenuto" y "Allegro giusto", esquema formal. 


\section{LAS OBRAS EN CONTEXTO}

Para la ubicación de estas obras del período argentino de Julián Bautista en el entramado textual de su época es oportuno atender a los dos grandes campos de referencialidad presentes en ellas, uno ligado a la cultura española y otro a la modernidad musical de su generación. En relación con el primero, en el plano peritextual ${ }^{10}$, es posible apreciar una configuración del espacio cultural al que el compositor desea aludir, ya que todos los títulos guardan una conexión directa con un pasado remoto. En este sentido es posible apreciar la presencia de el Siglo de Oro español con la obra de Pedro Calderón de la Barca La dama duende, la edad media y el renacimiento en los Catro poemas galegos (donde aparecen personajes del siglo IX, XIII, XV y XVI); el romancero español y el último rey visigodo en Romance del Rey Rodrigo; o un género musical de origen renacentista como es la fantasía, en Fantasía española.

Otro aspecto relacionado con el peritexto es la relación con poetas y artistas que aparecen en estas obras, los que configuran una escena directamente ligada a los ideales de la generación del 27, la II República y, en parte, al galleguismo. Aquí hay que reseñar que además de Lorenzo Varela y Luis Seoane, autores de los poemas y los grabados que forman parte de Catro poemas galegos, se debe citar a Rafael Alberti y Tania León que tienen una incidencia directa en La dama duende, ya que son los autores de la adaptación para el cine de esta obra que es de donde proviene la suite de Bautista. También este ámbito favorable a la república o al antifascismo se hace presente en los nombres propios mencionados en la dedicatoria de los Catro poemas..., que son los de Juan José Castro y su esposa Raquel Aguirre.

Dentro del plano textual o sonoro se encuentran confirmaciones de estas referencias. En el lenguaje verbal de la cantata resultan especialmente llamativos los versos con los que se abre y cierra la obra, "Madre, España, / ¡Ay de ti! Madre España;". Aunque el compositor no indica la versión del romancero del que extrae la poesía, comparando el texto de la obra con la versión de este romance en Flor nueva de Romances Viejos de Ramón Menéndez Pidal se aprecia un profundo trabajo de adaptación y ordenamiento "para ser puesto en música" como indica el autor en la partitura. Por su parte, los Catro poemas... contienen elementos fuertemente marcados por la ideología galleguista del poeta, autor de los versos, como del artista plástico, que realizara los grabados que dieron origen a esos poemas. Si bien Bautista, con ascendencia gallega por parte de madre, nunca se significó dentro de alguna de las corrientes ideológicas del galleguismo (de hecho, esta es la única obra donde aborda esta temática), no cabe duda de que aquí decide participar en un proyecto de ensalzamiento de ese ámbito cultural que hace del medievalismo y el celtismo sus marcas diferenciadoras de la cultura y tradición española.

Un primer elemento significativo es el empleo del gallego que en esos años estaba prohibido por el régimen de Franco y su utilización no estaba exento de cierta controversia entre los diferentes grupos políticos gallegos representados en Argentina ${ }^{11}$. En ese idioma se rescatan figuras significativas dentro de la construcción idealizante de lo gallego que había

10 Para abordar los diferentes planos de referencialidad en una obra musical se utiliza la división entre peritexto y epitexto propuesta por Gerard Genette en Umbrales (2001). A partir de ello se considera que para el caso del texto musical, el peritexto se limita a los títulos, subtítulos, lemas, prefacios, dedicatorias y todo tipo de indicaciones que aparezcan en la partitura, y el epitexto se refiere a todos los mensajes en torno a la obra que están fuera de los límites de la misma (en soportes mediáticos, entrevistas, críticas, etc., o comunicaciones privadas).

11 Es oportuno recordar que en esta época no eran mayoría las publicaciones de la colectividad gallega en Buenos Aires que se editaban solamente en gallego, y tampoco eran muchos los representantes institucionales que lo usaban en los actos oficiales. 
comenzado en la segunda mitad del siglo XIX. Así aparecen "Maria Pita", heroína gallega ligada a la defensa de Galicia contra la brigada británica en el siglo XVI; "Ruy Xordo", hidalgo del siglo XV ligado a la "primera guerra irmadiña" o Irmandade Fusquenlla que se enfrenta a los abusos de los señores feudales; "María Balteira" (María Pérez apodada La Balteira), soldadeira ${ }^{12}$ que es fuente de inspiración en varias de las cántigas de escarnio de la corte de Alfonso X aunque en este poema Varela destaca su actividad de bailarina dentro de un fuerte carácter laudatorio; y el obispo Ataúlfo en "O touro...", al que la leyenda presenta como triunfador, por su bondad, en su enfrentamiento al toro (prueba impuesta como "Juicio de Dios") al que es sometido injustamente por las calumnias de sus enemigos. En todas estas relecturas del pasado destaca el propósito de modernizar o actualizar esos referentes de la tradición, que ya está presente en la representación gráfica de Seoane, que luego pasa a los poemas de Varela, y que Bautista no duda en reforzar con los rasgos estilísticos-musicales comentados en párrafos anteriores. Esa modernización, marcada por la ideología de izquierda de sus autores contrasta con la perspectiva conservadora y ligada al pensamiento eclesiástico desde la cual se construyó y desarrolló el primer galleguismo en el siglo XIX.

En cuanto a la intertextualidad en el lenguaje musical, es posible percibir la presencia de diferentes alusiones. Entre ellas destacan la relacionada con el ritmo y el fraseo de la jota, los giros cadenciales modales o los característicos melismas rítmico-melódicos del flamenco en la Fantasía española. También en esta obra se puede indicar que el tercer tema es, prácticamente, una cita de los compases 27-29 de "Evocación" de Iberia de Albéniz. Mientras en la cantata las alusiones modales siguen presentes, en los Catro poemas... se hace evidente la alusión a la música medieval o al organum con el recurso de los paralelismos de quintas y cuartas. También en esta obra, Eva Moreda Rodríguez aprecia presencia de la música tradicional gallega en "Maria Pita" y "O touro...", en el primer caso con rasgos ligados a la alborada gallega y en el segundo aspectos métricos y rítmicos asociados a la muñeira (Moreda Rodríguez 2016: 85-86).

En el campo de las referencias ligadas a la modernidad musical de su generación, siguiendo lo planteado en los párrafos anteriores, es posible observar que en las obras sin alusiones directas a la música o cultura española los títulos remiten al campo de la música académica y, más puntualmente, al clasicismo. Solamente el cuarteto de cuerdas contiene una dedicatoria, "A la señora Clara Goreloff" (Presidenta en esos años de la Asociación de Conciertos de Cámara), y la Segunda sinfonía incluye el subtítulo de "Ricordiana" debido a que con ella Bautista participó y obtuvo el "Primer premio del Concurso Latino Americano de Composición (1958) organizado por Ricordi Americana S. A. ${ }^{13 "}$.

En el campo intertextual en estas composiciones el proceso de ocultamiento o deformación de los procedimientos utilizados para establecer los centros tonales pueden asociarse a la parodia, tomando este concepto en el sentido que lo definen Genette o Hutchon. Es decir, según Genette “ôda, es el canto; para: ‘a lo largo de`, ‘al lado〉; parôdein, de ahí parôdia, sería (?) el hecho de cantar al lado, cantar en falsete, o con voz, en contracanto -contrapunto-, o incluso cantar en otro tono: deformar, pues, o transportar una melodía (Genette 1989: 20 [Resaltados en el original])". Por su parte Hutcheon puntualiza:

[E]l prefijo para tiene dos significados casi contradictorios. [...] A partir del sentido más común -el para como <rente a〉o <contra>-, la parodia se define como <contracanto`, como oposición o contraste entre dos textos. [...]. Ahora bien, en griego, para

12 Cantora y bailarina que acompañaba el canto de juglares o trovadores (N. del E.)

13 Así consta en la portada de la partitura editada por Ricordi Americana (1959). 
quiere también decir ‘al lado de`, lo que sugiere más bien un acuerdo, una intimidad y no un contraste (Hutcheon 1992: 178).

Teniendo en cuenta estas definiciones, no es difícil percibir que, por ejemplo, la cadencia inicial del primer movimiento de la Sinfonía breve es una parodia de la característica cadencia empleada en el barroco y el clasicismo para marcar la tonalidad de la obra. Aquí, en contraposición a la directa relación V-I, tanto el acorde de dominante como el de tónica aparecen con apoyaturas o incompletos (véase $\mathrm{Ej}$. 9), pero además entre ellos se intercala un pasaje con, también, apoyaturas y saltos. De manera que este pasaje no se contrapone o intenta ridiculizar el enlace cadencial, por el contrario, sigue íntimamente ligado a la idea de marca tonal. Pero lo hace con un cierto grado de ironía, imprescindible en toda parodia, que intenta reforzar en la percepción del oyente que esos referentes tonales aparecerán alejados de la obviedad causada por tres siglos de armonía tonal y que, por el contrario, se manifestarán enmascarados o transformados. Algo semejante se puede decir, solo por mencionar otro ejemplo, del recurso relacionado con el ground o el pasacalle en el segundo movimiento de la misma sinfonía. Aunque aquí la relación se establece con un género y ello llama la atención del receptor acerca del hecho de que no solo la tonalidad se encuentra transfigurada, sino también los géneros relacionados con el desarrollo y consolidación de la misma lo están en este lenguaje compositivo del siglo XX. Pero sin duda estas apreciaciones se pueden extrapolar a muchos momentos de las últimas composiciones de Bautista. Así la presencia de doce sonidos o la exposición de un material temático con saltos de cuartas aumentadas sobre un acorde de séptima que se produce en su cuarteto de cuerda, son una manifestación más de esta intención de deformar y al mismo tiempo reafirmar la ideación, e incluso la supremacía, tonal.

En las mencionadas alusiones a los principios dodecafónicos y a motivos temáticos que rozan lo atonal, teniendo en cuenta el conjunto de la obra, es posible apreciar una referencia a las composiciones de Stravinski de los años cincuenta. Aunque aquí es necesario mencionar también a Alberto Ginastera, quien en esa década hace un empleo libre del principio serial, semejante a los descritos en la obra de Bautista. Otro compositor al que se sigue aludiendo es a Manuel de Falla y su visión de la obra de Scarlatti, especialmente su concreción en el Concerto para clave y cinco instrumentos. Esto se puede apreciar, por ejemplo, en el inicio del tercer movimiento de la Sinfonía breve, donde la semejanza con ese referente alcanza al diseño de las dos primeras ideas temáticas. Sin embargo, mientras en el primero de esos temas la escritura orquestal puede considerarse un paso más en la transposición sonora de la música del compositor del siglo XVIII, en la elaboración fraseológica del segundo el desarrollo expresivo se aleja bastante de las ideas de concisión y sobriedad perseguidas por la "escuela española". Esa expresividad que ya estaba presente en el desarrollo de la Fantasía y también aparece en la Segunda sinfonía, se torna más subjetiva y más cercana al expresionismo en el cuarteto. Para completar este campo de referentes musicales es oportuno recordar que Roberto García Morillo asociaba algunas de las obras de Bautista, entre ellas las sinfonías y el cuarteto, a "una aspereza y un dinamismo que recuerda a producciones análogas de Bèla Bartók (en los cuartetos) o Paul Hindemith (Mathis der Maler)" (García Morillo 1961: snp).

Teniendo en cuenta los dos campos referenciales, el de la cultura española y el de la modernidad musical, es posible determinar que la etapa argentina de Bautista es plenamente consecuente con los postulados de la modernización musical madrileña de los años treinta, aunque con particularidades ligadas a su inserción en el país de acogida y a su particular desarrollo creativo. La sustentación de un discurso musical basado en el planteamiento tonal, claridad estructural, texturas diáfanas y cierta cuota de expresividad es la principal impronta que dejaron en el compositor los principales ascendientes de la música madrileña 
de las décadas del veinte, Manuel de Falla, Adolfo Salazar y los compañeros de ruta del Grupo de los Ocho. Dentro de ese campo de acción el principal rasgo particular que desarrolla Bautista, como se abordó aquí, es el de la exploración de los límites de la tonalidad, con una preocupación permanente por buscar variantes de las estructuras acórdicas, la combinación de estas con diferentes organizaciones de alturas (modos, total cromático, series, etc.), la bimodalidad, la debilitación de la funcionalidad armónica en el discurso por medio de la inserción de pasajes de estructuras verticales no funcionales o la potenciación de la presencia de rasgos tonales por el contraste con pasajes atonales o seriales.

Todas esas características serán puestas en juego en las primeras obras realizadas por el compositor en Argentina, donde hace evidente su necesidad de significarse como artista español. En ese proceso de reafirmación de la identidad de procedencia no duda en recurrir a algunos de los tópicos adheridos a la cultura española en el siglo XIX. Así, en la Fantasía española recurre a lo andaluz dentro de un lenguaje veladamente postromántico alejándose, momentáneamente, del casticismo y scarlattismo que marcó la música de Falla y sus compañeros de ruta en los años veinte. Esta sobreexposición de lo español, mediante los tópicos más reconocibles en el extranjero, toma un cariz diferente cuando se torna hacia lo gallego, con el pretendido rescate de una cultura y una historia visual-poético-sonora arcaica, olvidada y sojuzgada. Aquí, su música se relaciona directamente con el Rexurdimento Galego decimonónico ${ }^{14}$, que aunque no tuvo repercusión en el Grupo de los Ocho, tiene continuidad como referente histórico de la reivindicación galleguista del siglo XX. Por su parte, La dama duende y el Romance del Rey Rodrigo sí tienen una inserción más directa en los ideales de la Generación del 27, debido a la importancia que este movimiento literario y artístico dio al Siglo de Oro y al Romancero español como referentes para rescatar la cultura española de la decadencia de los siglos precedentes.

Pero estas composiciones no son una propuesta aislada en la Argentina de los años cuarenta y cincuenta. En un plano general, estas son solo un fragmento de lo que en un trabajo anterior se estudió como la tendencia hispanista en la música argentina, donde se comprobó que entre 1939 y 1949 se produjo un aumento considerable de composiciones con esta temática ${ }^{15}$. En este sentido es oportuno tener en cuenta lo que afirma Dora Schwarzstein, en relación con que "la izquierda intelectual argentina encontró a partir de la guerra de España una nueva identidad y fue uno de los sucesos europeos que más impactó sobre ella" (Schwarzstein 2001: 104). Además de este plano general, hay que recordar que algunas de las obras del compositor madrileño se suman a propuestas muy concretas dentro de esa tendencia. Así se puede hablar de una subtendencia centrada en canciones con textos en gallego o galaico-portugués, donde los Catro poemas galegos son el punto de partida para obras académicas que utilizan el gallego y determinados rasgos estilísticos, entre las que se pueden mencionar Dos cantos galegos (1945) y Dos cantares Galaicos portuguese del siglo XIII (1954) de Roberto Caamaño, con poesía de Rosalía de Castro y Joao Balseiro; Dos canciones de Rosalía de Castro (1948) y Cantares de amor (1951) de Juan José Castro, la segunda también con textos de Balseiro ${ }^{16}$. También el romancero ha sido fuente de numerosas canciones de compositores como Roberto García Morillo, Carlos Guastavino, Eduardo Grau, entre otros.

14 Proceso de recuperación de la lengua y la cultura gallega iniciado en la segunda mitad del siglo XIX, algunos de los referentes de este movimiento son Rosalía de Castro (1837-1885), Eduardo Pondal (1835-1917), Manuel Murguía (1833-1923) o Manuel Curros Enríquez (1851-1908).

15 Véase Ogas 2005. Allí se detallan más de medio centenar de obras con esta temática escritas entre 1939 y 1949, cantidad que casi triplica el número de composiciones con estas características realizadas entre 1900 y 1938.

16 Véase González 2010. 
Sin embargo, en este caso también es oportuno resaltar que el tema de Don Rodrigo será abordado por Alberto Ginastera en su ópera de 1964.

Si esta es una faceta de la integración del compositor a la cultura argentina, no es menos cierto que su relación con el modernismo de su generación tendrá un fácil entronque con el de sus contemporáneos argentinos. Si Ravel, Falla y Stravinski son los principales referentes del Grupo de Madrid, también lo son del Grupo Renovación (1929) argentino y de muchos de los compositores del país que dan a conocer sus primeros trabajos en la década de 1930. Aquí cabe destacar la figura de Juan José Castro con quien Bautista mantuvo una profunda amistad y, como es sabido, fue un compositor ligado al neoclasicismo argentino y, muy especialmente, a la figura de Manuel de Falla ${ }^{17}$. En las obras sin referencias hispánicas de Bautista es posible percibir la continuidad de los objetivos modernistas de la generación del 27 o de la Republica. Objetivos que están relacionados con esa búsqueda de sincronía con el ambiente musical internacional que compartían capitales como Madrid o Buenos Aires. Esas aspiraciones hacen que Bautista no dude en acercarse al neoexpresionismo, aunque sin abandonar la sintaxis tonal, de forma que profundiza en los ideales madrileños de los que es portador en su nueva tierra y engarza con la búsqueda de esos años de compositores argentinos más jóvenes que él como Alberto Ginastera, Roberto García Morillo, Pedro Sáenz o Marcelo Koc ${ }^{18}$.

En este punto es oportuno tener en cuenta lo que señala Hernán Vázquez en relación con los Festivales de Música de Caracas, en cuya segunda edición (1957) participa Bautista como representante de Argentina. Allí, según Vázquez, "se discutía en torno a la utilización de citas folclóricas y, además, técnicas compositivas 'actuales' en pos de un identidad musical latinoamericana" (Vázquez 2015: 19). También este autor apunta, a partir del trabajo de Eduardo Herrera, que Bautista, junto con Juan José Castro y Alberto Ginastera, participa en algunas de las reuniones con John P. Harrison (director asistente de la sección Humanidades de la Fundación Rockefeller) para organizar un centro de perfeccionamiento para jóvenes compositores latinoamericanos ${ }^{19}$. Por otra parte, esa búsqueda renovadora de Bautista también se puede asociar con la intención de mantener vigente su compromiso con la modernización musical española iniciada en los años veinte, frente a lo que consideraban como un estancamiento de la composición dentro del territorio español luego de la Guerra Civil. En este sentido él recorre un camino semejante al de Rodolfo Halffter, exiliado en México, aunque este introducirá el dodecafonismo de una forma más decidida en su obra, mientras Bautista nunca abandonará completamente cierta ideación tonal y rasgos expresivos de su primera época ${ }^{20}$.

17 Recordemos que Bautista compartió con Castro, por ejemplo, el proyecto del Conservatorio de Música de Puerto Rico.

18 Véase Ogas 2010: 144-152. Omar Corrado, por su parte, llama la atención acerca de la incorporación del dodecafonismo también a la manera de Stravinski, que realiza Luis Gianneo (18971968) en sus obras de comienzos de los sesenta. Destacamos este caso por tratarse de un compositor ligado, principalmente, al neoclasicismo con rasgos de la música popular argentina y de una edad semejante a la de Bautista, lo que permite ver que en el contexto musical argentino la preocupación por incorporar estas técnicas no era solo de los compositores más jóvenes (Corrado 1997: 169-171).

19 De estas reuniones surge luego, en 1960, el Centro Latinoamericano de Altos Estudios Musicales del Instituto Di Tella (CLAEM) dirigido por Alberto Ginastera.

20 Véase Ogas 2010. 


\section{CONCLUSIONES}

En la música de concierto compuesta en Argentina por Julián Bautista es posible apreciar, siguiendo la terminología de Kristeva, la impronta de ese ideologema ${ }^{21}$ que marcó a su generación, que no es otro que el de la modernidad de España. Una modernidad a la que Bautista en su discurso musical entiende ligada a los modelos del clasicismo del siglo XVIII, ya que, desde la perspectiva de su época, ese es el momento de la historia de Occidente donde España se aísla del progreso europeo. La lectura de lo clásico como modernidad tiene en Bautista, como en la mayoría de sus contemporáneos, dos principios intrínsecamente unidos: uno de ellos es el convencimiento de que toda renovación debe seguir ligada al equilibrio y la claridad de los principios clásicos; el otro es la autoexigencia de que en cada obra se debe experimentar y renovar las relaciones internas del texto.

En esas relaciones internas, entre la ideación de las temáticas musicales y su tratamiento, es donde se puede apreciar los cambios de enfoque que el compositor va realizando y, en cierta medida, las circunstancias que rodean su producción. Es así que atendiendo a la temática hispánica se comprueba que su producción en Argentina presenta un proceso de representación de lo español que progresivamente se va alejando de la exposición de los tópicos más evidentes de la tradición, para recurrir a una idealista y reivindicativa reconstrucción del pasado, a alusiones más veladas o a tomar como referencia la suma de resignificaciones precedentes del patrimonio musical. Proceso que coincide en el tiempo con el paso de la etapa donde los exiliados estaban convencidos de que Franco iba a caer de un momento a otro, a aquella donde se ven obligados a aceptar que no podrán regresar a España por un largo tiempo o nunca, como le sucedió a Bautista. La fase de aceptación de la continuidad del dictador en España concuerda con el último grupo de obras de Bautista que comienza con el Romance del Rey Rodrigo. Si este en su poesía expresa la resignación ante la pérdida de España por el rey visigodo, la adaptación de Bautista no puede dejar de asociarse a la situación republicana de esos años y la obligada aceptación personal de una patria perdida. Más aún si se tiene en cuenta que en las obras siguientes el compositor se centra en las particulares indagaciones tonales y formales que él, como parte del Grupo de los Ocho, había propugnado en la década de 1930 y lo español pasa a un plano más subjetivo.

Será ese compromiso con España y la modernidad el que facilite la integración de Bautista en la vida musical argentina. En esta integración confluyen aspectos estéticos e ideológicos compartidos por el compositor español y una parte de sus colegas argentinos. Ya que, en la década de 1940 en Buenos Aires significarse como español o descendiente de españoles fue para muchos artistas y músicos una forma de denunciar la situación de España y de posicionarse contra el fascismo nacional e internacional. Por ello la música de un español exiliado o emigrado no solo no era vista como extraña, sino que era acogida calurosamente, como sucedió con Bautista, Falla o Pahissa. Pero no solo la temática hispanista, como expresión de ese estado de vigilia ante la situación española, es un punto de encuentro en los cuarenta, también lo son los referentes neoclasicistas que de un lado y otro del Atlántico habían sido el motor de la renovación musical en las décadas precedentes. En este sentido la música de Falla, Ravel o Stravinski conforman el escenario común donde confluyen las composiciones del recién llegado y muchos de sus colegas de Argentina.

Por su parte, la concienzuda y particular dedicación a la renovación del lenguaje musical dentro de los límites de la tonalidad y su acercamiento a una expresión personal

21 Según Julia Kristeva un ideologema es "aquella función intertextual que puede leerse 'materializada' a los distintos niveles de la estructura de cada texto, y que se extiende a lo largo de todo su trayecto, confiriéndole sus coordenadas históricas y sociales” (Kristeva 1981: 15). 
con rasgos de una sutil transfiguración del lenguaje sonoro de las últimas obras de Bautista también aparecen ligadas a las corrientes compositivas del contexto porteño. Ya que en los cincuenta, probablemente las experiencias personales de los exilios, el temor a los nacionalismos (tanto a nivel internacional como local) y la presencia de las nuevas corrientes compositivas que se gestaban en esos años, incidieron en la decisión de Bautista y muchos de sus colegas argentinos de ubicar en un segundo plano las alusiones a las músicas locales e indagar en las posibilidades de técnicas compositivas generadas fuera o más allá del neoclasicismo. Por todo ello es posible afirmar que, tanto por su temática como por su lenguaje compositivo, las obras argentinas de concierto de Julián Bautista pueden ser consideradas como plenamente integradas en el ambiente musical de Buenos Aires de las décadas centrales del siglo XX. En definitiva, estas composiciones y el contexto que, con sus características, convocan se pueden leer como el testimonio sonoro de una particular confluencia compositiva hispanoamericana.

\section{BIBLIOGRAFÍA}

Angenot, Marc

2010 El discurso social. Los límites históricos de lo pensable y lo decible. Buenos Aires: Siglo XXI.

Corrado, OMAR

1997 Luis Gianneo - Juan Carlos Paz: encuentros y bifurcaciones en la música argentina del siglo XX. Cuadernos de Música Iberoamericana, 4, pp. 145-177.

Cros, Edmond

2009 La sociocrítica. Madrid: Arco Libros.

De Marchis, Giorgio P. y Beatriz Hernanz Angulo.

2013 "Modelo de relaciones retóricas para la integración de la imagen y el texto", Icono 14, XI/1, pp. 27-44.

De Persia, Jorge

2004 Julián Bautista. Madrid: Biblioteca Nacional de España.

García López, José Ángel

2015 "Aproximación Ecdótica ás Edicións da Obra Poética de Lorenzo Varela", Madrygal. Revista de Estudios Gallegos, № 18, pp. 95-105.

García Morillo, Roberto

1961 "Julián Bautista", Revista ARS, XXII/93, snp.

Genette, Gerard

1989 Palimpsestos. La literatura en segundo grado. Madrid: Taurus.

2001 Umbrales. México, DF: Siglo XXI.

Ginastera, Alberto

1961 "El pensamiento de Julián Bautista", Revista ARS, XXII/93, snp.

GonzÁlez, Mirta

2010 Déjame tu voz. La poesía española en la canción de cámara argentina. Oviedo: Edición de la autora.

HALFFTER, RODOLFo

1938 "Julián Bautista”, Música, 1 [Barcelona], pp. 9-23.

Heine, Christiane

2013 "El pensamiento armónico de Julián Bautista en teoría y práctica. Del Estudio comparativo de los principales Tratados de Armonía (1934-1935) a Suite all'antica y Barrio de Córdoba", Recerca musicologica, 20-21, pp. 331-353. 
Hutcheon, Linda

1992 "Ironía, sátira, parodia. Una aproximación pragmática a la ironía”. De la ironía a lo grotesco. Editado por Hernán Silva. México: Universidad Autónoma Metropolitana Iztapalapa, pp. 173-193.

Kristeva, Julia

1981 El texto de la novela. Barcelona: Lumen.

LENDVAI, ERNŐ

1979 Béla Bartók : an analysis of his music. Londres: Kahn \& Averill.

Menéndez Pidal, Ramón

2010 Flor nueva de romances viejos [1928]. Madrid: Espasa.

Moreda Rodríguez, Eva

2012 "Francoism and the Republican exiles: the case of the composer Julián Bautista (1901-61)", Twentieth-Century Music, VIII/2, pp. 153-173

2015 "Transatlantic Networks in the Correspondence of Two Exiled Spanish Musicians, Julián Bautista and Adolfo Salazar", Journal of The Royal Musical Association, 140/1, pp. 93-119. Disponible en www.tandfonline.com/doi/full/10.1080/02690403.2015.1008864?scroll=to p\&needAccess=true [acceso: 19 de noviembre de 2019].

2016 Music and Exile in Francoist Spain. Abingdon: Routledge.

Ogas, Julio

2005 "Primera década de la tendencia hispanista en la música argentina (1939-1949)". Joaquín Rodrigo y la música española de los años cuarenta. Editado por Javier Suárez Pajares. Valladolid: Universidad de Valladolid, pp. 79-93.

2010 Música para Piano en Argentina (1929-1983). Mitos, tradiciones y modernidades. Música argentina para piano. Madrid: ICCMU.

2010 "Elección estilística y procesos de significación en la obra para piano de Rodolfo Halffter", Revista de Musicología, XXXI/1-2, pp. 329-342.

2011 "El texto inacabado. Tipologías intertextuales, música española y cultura”. Creación musical, cultura popular y construcción nacional en la España Contemporánea. Editado por Celsa Alonso. Madrid: ICGMU, pp. 233-252.

Palacios, María

2008 La renovación musical en Madrid durante la dictadura de Primo de Rivera. Madrid: Sociedad Española de Musicología.

PiQuer, Ruth

2011 "El concepto estético de clasicismo moderno en la música española (1915-1939)". Tesis doctoral. Madrid, Universidad Complutense de Madrid (Repositorio). Disponible en https:// eprints.ucm.es/13304/ [acceso: 19 de noviembre de 2019].

Scarabino, Guillermo

2000 El Grupo Renovación (1929-1944) y la nueva música en la Argentina del siglo XX. Buenos Aires, Ediciones de la Universidad Católica Argentina.

SCHWARZSTEIN, DORA

2001 Entre Franco y Perón. Memoria e identidad del exilio republicano español en Argentina. Barcelona: Crítica.

Torralba, José

1982 Cancionero popular de la provincia de Cuenca. Cuenca: Diputación Provincial de Cuenca.

VÁZquez, HERNÁN

2015 Conversaciones en torno al CLAEM. Buenos Aires: Instituto Nacional de Musicología "Carlos Vega". 